\title{
Preparation of alumina ceramics from a slurry with cellulose nanofibers
}

\author{
Takaaki NAGAOKA ${ }^{1, \dagger}$, Ken'ichiro KITA $^{1}$ and Naoki KONDO ${ }^{1}$ \\ ${ }^{1}$ National Institute of Advanced Industrial Science and Technology (AIST), \\ 2266-98 Shimo-Shidami, Moriyama-ku, Nagoya 463-8560, Japan
}

\begin{abstract}
The effect of adding cellulose nanofibers (CNFs), which are among the new materials attracting attention recently, to aqueous alumina $\left(\mathrm{Al}_{2} \mathrm{O}_{3}\right)$ slurry was evaluated in order to investigate the possibility of using $\mathrm{CNFs}$ as a new forming aid. $\mathrm{Al}_{2} \mathrm{O}_{3}$ slurries with a small amount of $\mathrm{CNFs}(>0.1 \%)$ showed significant thixotropy. The slurry with $0.1 \%$ CNFs was cast in a gypsum mold, and $\mathrm{Al}_{2} \mathrm{O}_{3}$ green bodies with no cracks could be prepared after demolding and drying in air. Then $\mathrm{Al}_{2} \mathrm{O}_{3}$ sintered bodies with no cracks could be obtained after heating at $1600^{\circ} \mathrm{C}$ for $2 \mathrm{~h}$. The densities of the green bodies and sintered bodies prepared from the slurry with CNFs were lower, however, than those prepared from the slurry without CNFs. In addition, the bending strength of sintered bodies prepared from the slurry with CNFs was also lower than that of those prepared from the slurry without CNFs. In order to prepare dense $\mathrm{Al}_{2} \mathrm{O}_{3}$ sintered bodies, it will be necessary to improve the density of the green bodies prepared from slurry with CNFs added.

(c)2018 The Ceramic Society of Japan. All rights reserved.
\end{abstract}

Key-words: Cellulose nanofiber (CNF), Alumina, Slurry, Flow curve, Slip casting, Sintering, Microstructure Strength

[Received September 4, 2017; Accepted December 18, 2017]

\section{Introduction}

Cellulose nanofibers (CNFs), which are of tree origin, are attracting attention due to their excellent physical properties, such as high specific strength and a low thermal expansion coefficient. ${ }^{1), 2)}$ In recent years, industrially available CNFs have been developed by physically and chemically fibrillating cellulose, one of the constituents of trees. ${ }^{3)-6)}$ They are several nanometers in width and several micrometers in length. They can also easily be dispersed in water. ${ }^{6)}$ They have consequently been studied extensively as a new material for uses as thickeners and reinforcing fibers. ${ }^{7)-12)}$ However, there are few studies on the application of CNFs to ceramics processes. ${ }^{13), 14)}$ If CNFs have potential as a wet-forming aid for ceramics, they can be expected to be widely used in the wet-forming processes. One of the positive expectations is that the addition of CNFs to slurry might suppress the generation of cracks in samples during drying shrinkage. On the other hand, CNFs might reduce the density of the green bodies. Furthermore, CNFs in green bodies might exert a negative influence on the sintered bodies (for example, generation of cracks) due to thermal decomposition during heating. In order to apply CNFs as an additive for ceramics processing, therefore, especially as a forming aid, it will be necessary to acquire

Corresponding author: T. Nagaoka; E-mail: t.nagaoka@ aist.go.jp various basic data on the process from raw materials preparation to sintered bodies production.

In this study, CNFs were applied to wet forming of alumina $\left(\mathrm{Al}_{2} \mathrm{O}_{3}\right)$ ceramics, which are typical oxide ceramics that are widely used as structural components. First, aqueous $\mathrm{Al}_{2} \mathrm{O}_{3}$ slurries with CNFs were prepared, and green bodies were then made by slip casting them using gypsum molds. After casting, the green bodies were fired to prepare $\mathrm{Al}_{2} \mathrm{O}_{3}$ sintered bodies. Finally the characteristics of the slurries, the green bodies and the sintered bodies were evaluated.

\section{Experimental procedures}

Aqueous $\mathrm{Al}_{2} \mathrm{O}_{3}$ slurries were prepared by mixing commercially available high-purity $\mathrm{Al}_{2} \mathrm{O}_{3}$ powder (160SG-4, $\mathrm{Al}_{2} \mathrm{O}_{3}>99 \%, 6 \mathrm{~m}^{2} / \mathrm{g}$, Showa Denko KK), distilled water, water-soluble acrylic dispersant and CNF aqueous dispersion (REOCRYSTA, water dispersions of $2 \%$ CNFs, Dai-ichi Kogyo Seiyaku Co., Ltd.). A planetary centrifugal vacuum mixer without mixing media was used to mix these materials. The composition of the slurries was 100 parts by weight of $\mathrm{Al}_{2} \mathrm{O}_{3}$ powder, 25 parts by weight of water (containing water of $\mathrm{CNF}$ aqueous dispersion), 1 part by weight of water-soluble acrylic dispersant and 0.1 or 0.2 part by weight of CNFs. By comparison, a slurry without CNFs was also prepared. $\mathrm{Al}_{2} \mathrm{O}_{3}$ slurries with 0.1 and 0.2 parts by weight of CNFs are referred to as slurry with $0.1 \%$ CNFs and with $0.2 \%$ CNFs, respectively. Green 
bodies were prepared by casting the slurries in gypsum molds, followed by demolding and drying the samples at room temperature in air. With a gypsum mold, it is possible to cast a green body approximately $9 \mathrm{~cm}$ in length, $6 \mathrm{~cm}$ in width and less than $1 \mathrm{~cm}$ in thickness. After drying, the green bodies were heated at $5^{\circ} \mathrm{C} / \mathrm{min}$ and fired at $1600^{\circ} \mathrm{C}$ for $2 \mathrm{~h}$ in air. The green bodies and sintered bodies prepared from the slurries with/without CNFs are referred to as green bodies and sintered bodies with/without CNFs, respectively.

The thermal decomposition behavior of CNFs was measured using a simultaneous differential scanning calorimetry (DSC)-thermogravimetric analysis (TGA) instrument (SDT Q600, TA Instruments). REOCRYSTA, dried in air at $80^{\circ} \mathrm{C}$, was provided for the measurements. Measurement was conducted under conditions of a heating rate of $10^{\circ} \mathrm{C} / \mathrm{min}$ from room temperature to $1000^{\circ} \mathrm{C}$ in air flow $(100 \mathrm{ml} / \mathrm{min})$. The slurry characteristics were evaluated using a spindle type viscometer. The rotating speed of the rotor of the viscometer was varied from 0.3 to $60 \mathrm{rpm}$, and the (apparent) shear stress with respect to each (apparent) shear rate was measured. The flow curves of the sample slurries were then acquired from the measurements conducted while increasing and decreasing the rotating speed. The density of the green bodies was calculated based on their size and weight. The bulk density of the sintered bodies was measured by the Archimedes method. The relative density of the sintered bodies with respect to the density of $\mathrm{Al}_{2} \mathrm{O}_{3}\left(3.98 \mathrm{~g} / \mathrm{cm}^{3}\right)$ was also calculated. The bending strengths of the sintered bodies produced from the slurries with/without CNFs were measured by a 4-point bending method following JIS-R1601. The number of the respective test pieces was five, respectively. The microstructures of the green bodies and the sintered bodies were observed by scanning electron microscopy (SEM).

\section{Results and discussion}

Figure 1 shows the thermal analysis results for the CNFs dried at $80^{\circ} \mathrm{C}$. From the TG curve, weight loss was observed at from room temperature to about $100^{\circ} \mathrm{C}$ and from about $220^{\circ} \mathrm{C}$ to about $300^{\circ} \mathrm{C}$. Another weight loss

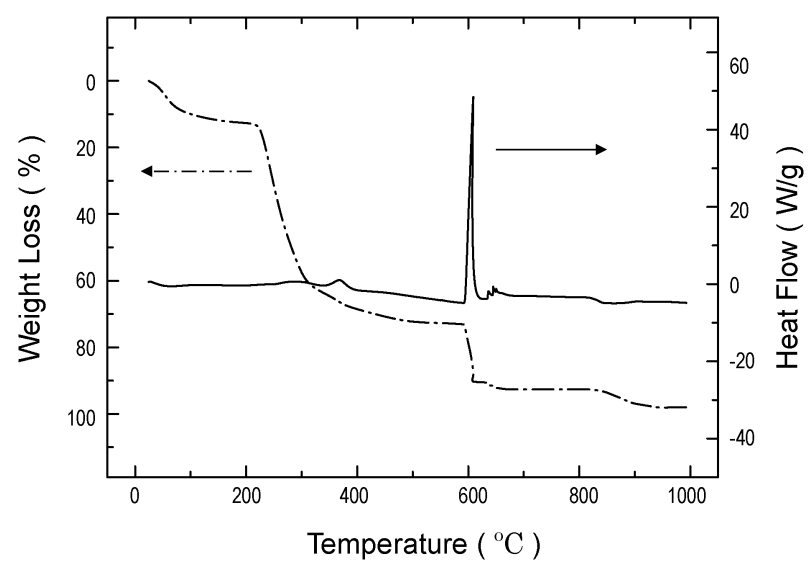

Fig. 1. DSC curve and TGA curve of the CNFs used in this study. with an exothermic peak was observed at around $600^{\circ} \mathrm{C}$. The weight loss to about $100^{\circ} \mathrm{C}$ was due to volatilization of water attached to CNFs. The weight loss starting from about $220^{\circ} \mathrm{C}$ corresponds to the dehydration reaction of cellulose. ${ }^{15)}$ This result is consistent with the CNFs remaining stable up to $200^{\circ} \mathrm{C} .^{16)}$ The weight loss and exothermic peaks at around $600^{\circ} \mathrm{C}$ are due to thermal decomposition of the CNFs.

Figure 2 shows the flow curves of the $\mathrm{Al}_{2} \mathrm{O}_{3}$ slurries with/without CNFs. In the flow curves of the slurry without CNFs, the shear stress gradually increased with increases in the shear rate, and the curve at the time of acceleration almost agreed with the curve at deceleration. On the other hand, when CNFs were added, a marked increase in shear stress was observed along with a slight increase in shear rate. In addition, the curve during acceleration did not coincide with that during deceleration, and a hysteresis loop was observed. The area drawn by this hysteresis loop increased with increases in the amount of CNFs added. That is, the thixotropy of the $\mathrm{Al}_{2} \mathrm{O}_{3}$ slurries became increasingly remarkable with increases in the amount of CNFs added.

In this study, green bodies were prepared from slurry with $0.1 \% \mathrm{CNFs}$, since slurry with $0.2 \% \mathrm{CNFs}$ has low fluidity and proved difficult to cast in gypsum molds. No cracks were observed on the surfaces of the obtained green bodies with CNFs shown in Fig. 3(a). No cracks were observed on the surfaces of the green bodies without CNFs, either. Thus, the effect of CNFs as reinforcing fibers was not clarified. In order to further clarify the effect of CNFs as reinforcing fibers, comparison under more severe conditions, such as rapid drying in the oven, a lower $\mathrm{Al}_{2} \mathrm{O}_{3}$ content in the slurry, etc., needs to be conducted as a future task.

The density of the green bodies with CNFs $\left(2.27 \mathrm{~g} / \mathrm{cm}^{3}\right)$ was lower than that of those without CNFs $\left(2.43 \mathrm{~g} / \mathrm{cm}^{3}\right)$. Figure 4 show SEM photographs of the fracture surfaces of green bodies with/without CNFs, respectively. Though it was difficult to make a quantitative comparison from the fracture surface observations, the microstructure of the green bodies with CNFs is somewhat looser than that of

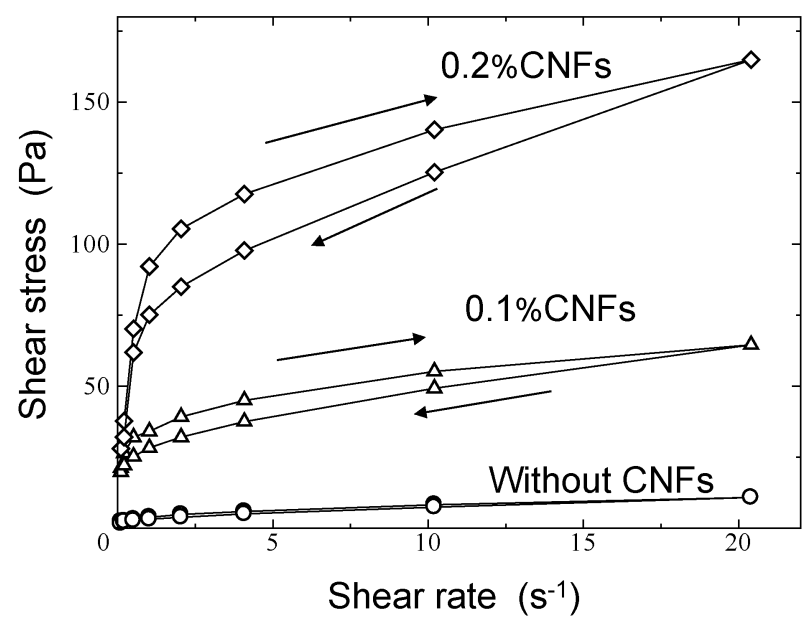

Fig. 2. Flow curves of $\mathrm{Al}_{2} \mathrm{O}_{3}$ slurries with/without CNFs. 

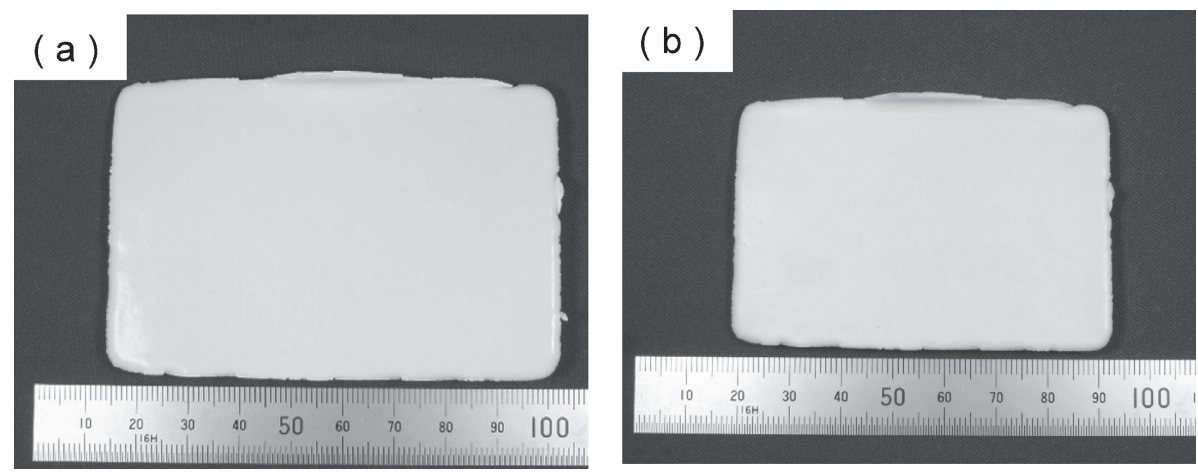

Fig. 3. Photographs of $\mathrm{Al}_{2} \mathrm{O}_{3}$ cast samples with $0.1 \%$ CNFs (a) before sintering and (b) after sintering.
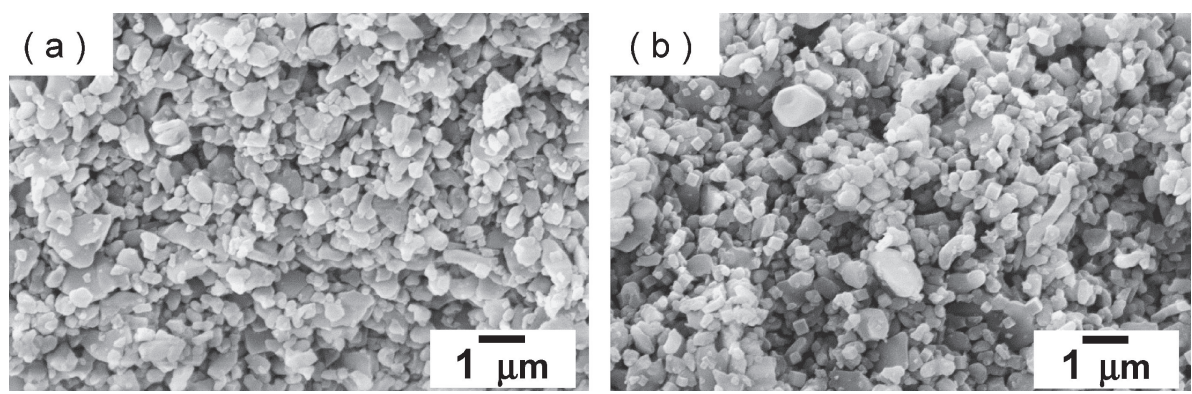

Fig. 4. SEM photographs of the fracture surfaces of green bodies (a) without CNFs and (b) with $0.1 \%$ CNFs.

Table 1. Some properties of $\mathrm{Al}_{2} \mathrm{O}_{3}$ sintered bodies with/without CNFs

\begin{tabular}{cccc}
\hline \multirow{2}{*}{ CNF Content } & \multicolumn{2}{c}{ Density } & $\begin{array}{c}\text { Flexural } \\
\text { Strength } \\
(\mathrm{MPa})\end{array}$ \\
\cline { 2 - 3 } & $\begin{array}{c}\text { Bulk Density } \\
\left(\mathrm{g} / \mathrm{cm}^{3}\right)\end{array}$ & $\begin{array}{c}\text { (Relative Density) } \\
(\%)\end{array}$ & $\begin{array}{c}\text { (\%) } \\
0.1 \%\end{array}$ \\
3.80 & $(95.5)$ & $265.6 \pm 15$ \\
Free & 3.92 & $(98.5)$ & $403.4 \pm 20$ \\
\hline
\end{tabular}

those without CNFs, as shown in Fig. 4(b). Observation of CNFs, which were predicted to be dispersed among the $\mathrm{Al}_{2} \mathrm{O}_{3}$ particles, was attempted, but no fibers that appeared to be CNFs were found, as shown in Fig. 4(b). The CNFs were too small to observe using a conventional SEM.

No cracks were observed on the surfaces of the sintered bodies without CNFs or with CNFs, either, as shown in Fig. 3(b). Under the experimental conditions of this study [amount of CNFs added ( 0.1 part by weight) and heating rate of the samples $\left.\left(5^{\circ} \mathrm{C} / \mathrm{min}\right)\right]$, therefore, it was revealed that there was no cracking due to thermal decomposition of the CNFs. Table 1 shows the results of the average density and the 4-point bending strength of the sintered bodies. The sintered bodies without CNFs were at almost full density $\left(3.92 \mathrm{~g} / \mathrm{cm}^{3}\right.$, relative density $\left.98.5 \%\right)$, but those with $0.1 \%$ CNFs showed a slightly lower density $\left(3.80 \mathrm{~g} / \mathrm{cm}^{3}\right.$, relative density $95.5 \%$ ). The average bending strength of the sintered bodies without CNFs was $403.4 \mathrm{MPa}$, but that of the sintered bodies with $0.1 \%$ CNFs was $265.6 \mathrm{MPa}$. Figure 5 shows SEM photographs of the fracture surfaces of sintered bodies with/without CNFs. As shown in Fig. 5(a), sintered bodies without CNFs have a microstructure with almost no voids. As shown in Fig. 5(b), on the contrary, sintered bodies with $0.1 \%$ CNFs have a microstructure containing some voids with diameters of about 1 micron. These voids reduced both the density of the sintered bodies and their bending strength. This $\mathrm{Al}_{2} \mathrm{O}_{3}$ sintered body with CNFs was fired further at $1600^{\circ} \mathrm{C}$ for $2 \mathrm{~h}$, but the density of the re-sintered body was $3.80 \mathrm{~g} / \mathrm{cm}^{3}$, showing no improvement. This result indicates that the low density of the sintered bodies with CNFs was not due to insufficient firing but to the addition of CNFs.

As mentioned above, the density of the green bodies and the sintered bodies prepared from $\mathrm{Al}_{2} \mathrm{O}_{3}$ slurry with CNFs was lower than that of those prepared from slurry without CNFs. In the case of silicon nitride $\left(\mathrm{Si}_{3} \mathrm{~N}_{4}\right)$, the density of the green bodies prepared from slurry with 0.2 mass $\%$ CNFs was lower than that of those without CNFs, but the density and bending strengths of the sintered bodies with and without CNFs were similar. ${ }^{14)}$ One possible explanation for the differences between $\mathrm{Al}_{2} \mathrm{O}_{3}$ and $\mathrm{Si}_{3} \mathrm{~N}_{4}$ is the sintering mechanism. Sintering of $\mathrm{Si}_{3} \mathrm{~N}_{4}$ is usually conducted under liquid-phase sintering conditions. The presence of the liquid phase should enhance mass transfer and densification. On the contrary, the sintering of $\mathrm{Al}_{2} \mathrm{O}_{3}$ in this study was conducted under solid-phase sintering conditions. Mass transfer was limited, which led to lower density. A detailed investigation is in progress to confirm the above proposition.

Improvement of the density of green bodies with CNFs will be necessary to obtain dense $\mathrm{Al}_{2} \mathrm{O}_{3}$ ceramics. Since slurry with CNFs had higher viscosity and thixotropy, as shown in Fig. 2, movement and packing of $\mathrm{Al}_{2} \mathrm{O}_{3}$ particles under conditions of CNF dispersion was limited during slip casting in gypsum molds, and the density of the green bodies was reduced as a result. Some techniques are therefore required to enhance the movement and packing of 

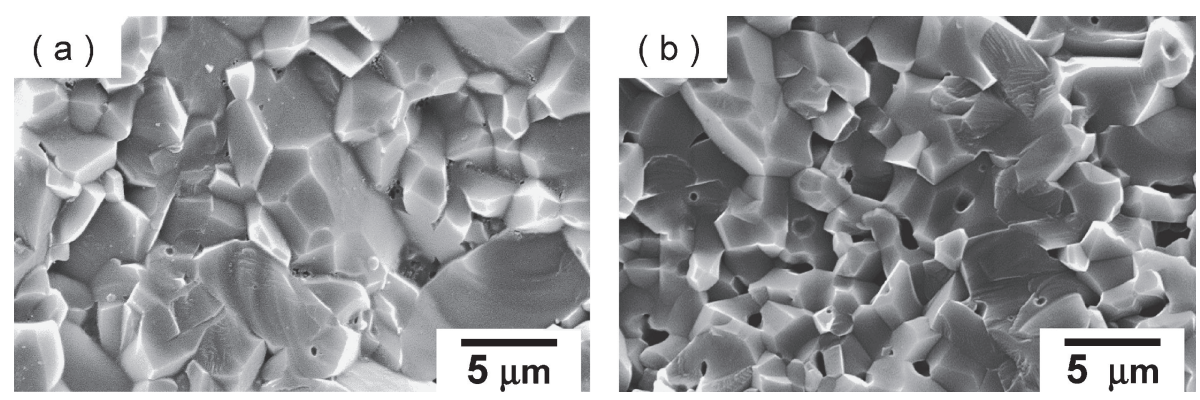

Fig. 5. SEM photographs of the fracture surfaces of sintered $\mathrm{Al}_{2} \mathrm{O}_{3}$ bodies (a) without CNFs and (b) with $0.1 \%$ CNFs.

$\mathrm{Al}_{2} \mathrm{O}_{3}$ particles. One possible technique is the addition of vibration of the gypsum mold, which is often used in product manufacturing processes. The advisability of using this technique is now under examination.

\section{Conclusions}

The effect of adding CNFs to aqueous $\mathrm{Al}_{2} \mathrm{O}_{3}$ slurry was evaluated in order to investigate the possibility of using CNFs as a new forming aid. The slurries with a small amount of CNFs added showed significant thixotropic properties. Both green bodies with no cracks and sintered bodies with no cracks could be prepared, moreover, from slurry with CNFs added. The density of green bodies with CNFs and sintered bodies with CNFs was slightly lower than those without CNFs, however, and sintered bodies with CNFs had lower bending strength. With improvement of the properties of green bodies and sintered bodies containing CNFs and confirming their effectiveness as reinforcing fibers for green bodies, CNFs are expected to become a useful wet-forming aid.

\section{References}

1) D. H. Page and F. EL-Hosseiny, J. Pulp Pap. Sci., 9, 99-100, (1983).

2) T. Nishino, I. Matsuda and K. Hirao, Macromolecules,
37, 7683-7687 (2004).

3) K. Abe, S. Iwamoto and H. Yano, Biomacromolecules, 8, 3276-3278 (2007).

4) S. Iwamoto, K. Abe and H. Yano, Biomacromolecules, 9, 1022-1026 (2008).

5) T. Saito, Y. Nishiyama, J.-L. Putaux, M. Vignon and A. Isogai, Biomacromolecules, 7, 1687-1691 (2006).

6) T. Saito, S. Kimura, Y. Nishiyama and A. Isogai, Biomacromolecules, 8, 2485-2491 (2007).

7) Y. Okahisa, A. Yoshida, S. Miyaguchi and H. Yano, Compos. Sci. Technol., 69, 1958-1961 (2009).

8) K. Abe, F. Nakatsubo and H. Yano, Compos. Sci. Technol., 69, 2434-2437 (2009).

9) H. Fukuzumi, T. Saito, Y. Kumamoto, T. Iwata and A. Isogai, Biomacromolecules, 10, 162-165 (2009).

10) C.-N. Wu, T. Saito, S. Fujisawa, H. Fukuzumi and A. Isogai, Biomacromolecules, 13, 1927-1932 (2012).

11) K. Yutoh, Daiichi Kogyo Seiyaku Report, 573, 15-16 (2015) [in Japanese].

12) Y. Goi, Daiichi Kogyo Seiyaku Report, 577, 11-14 (2016) [in Japanese].

13) Japan Patent, JPA 2010-265153 [in Japanese].

14) N. Kondo, K. Kita and T. Nagaoka, J. Ceram. Soc. Jpn., 125, 588-590 (2017).

15) M. M. Tang and R. Bacon, Carbon, 2, 211-220 (1964).

16) T. Nishino, M. Kotera and M. Kimoto, Proc. 2nd Int. Cellulose Conf. 2007, p125, October (2007). 